\title{
EFEITO DA COMPACTAÇÃO NA PRODUTIVIDADE DE CULTIVARES DE SOJA EM LATOSSOLO VERMELHO ${ }^{(1)}$
}

\author{
Amauri Nelson Beutler ${ }^{(2)}$, José Frederico Centurion ${ }^{(3)}$, Maria Aparecida \\ Pessoa da Cruz Centurion ${ }^{(4)} \&$ Alvaro Pires da Silva $^{(5)}$
}

\begin{abstract}
RESUMO
Na agricultura moderna, o tráfego de máquinas sobre o solo é a principal causa da compactação, que, muitas vezes, causa decréscimos da produtividade de soja. O objetivo deste estudo foi avaliar o desenvolvimento de cultivares de soja, considerando os níveis de compactação do solo. Para tal, foi realizado um experimento em Jaboticabal, SP, em Latossolo Vermelho textura média. Os tratamentos de compactação foram: $T_{0}=0 ; T_{1^{*}}=1 ; T_{1}=1 ; T_{2}=2 ; T_{4}=4$ e $T_{6}=$ seis passadas, no mesmo local, de um trator de $11 \mathrm{t}$, uma ao lado da outra, perfazendo toda a superfície do solo. No tratamento $T_{1^{*}}$, a compactação ocorreu quando o solo estava mais seco para obter um menor nível de compactação. O delineamento experimental foi inteiramente casualizado em parcelas subdivididas (seis níveis de compactação e quatro cultivares), com quatro repetições. Foram coletadas amostras indeformadas de solo nas camadas de $0,03-0,06 ; 0,08-0,11 ; 0,15-0,18$ e 0,22-0,25 m, para determinação dos atributos físicos. Em dezembro de 2003, foram semeados os cultivares de soja (Glycine max) IAC Foscarin 31, MG/BR 46 (Conquista), BRS/MG 68 (Vencedora) e IAC 8-2. O cultivar de soja IAC Foscarim 31 foi o mais produtivo no Latossolo Vermelho, quando comparado aos cultivares MG/ BR 46 (Conquista), BRS/MG 68 (Vencedora) e IAC 8-2. Os valores de resistência do solo à penetração a partir dos quais a produtividade dos cultivares de soja decresceu foram de 2,24 a 2,97 MPa, conforme os cultivares.
\end{abstract}

Termos de indexação: resistência mecânica do solo, atributos físicos, Glycine max, densidade do solo.

\footnotetext{
(1) Recebido para publicação em agosto de 2004 e aprovado em setembro de 2006.

(2) Pós-Doutorando do Departamento de Solos e Adubos, Universidade Estadual Paulista - UNESP/FCAV. Via de Acesso Prof. Paulo Donato Castellane, s/nº, CEP 14870-000 Jaboticabal (SP). Bolsista da FAPESP. E-mail: amaurib@yahoo.com.br (3) Professor do Departamento de Solos e Adubos, UNESP/FCAV. Bolsista do CNPq. E-mail: jfcentur@fcav.unesp.br

${ }^{(4)}$ Professora do Departamento de Produção Vegetal, UNESP/FCAV.

(5) Professor do Departamento de Ciência do Solo, Escola Superior de Agricultural "Luiz de Queiroz" - ESALQ/USP. Caixa Postal 09, CEP 13418-900 Piracicaba (SP).
} 


\title{
SUMMARY: EFFECT OF COMPACTION ON SOYBEAN CULTIVAR YIELD IN HAPLUSTOX
}

\begin{abstract}
Machinery traffic in modern agriculture is the main cause of soil compaction, and it often affects soybean yields. The objective of this study was to evaluate the development of soybean cultivars in relation to soil compaction levels. An experiment was carried out on a sandy-loam Haplustox located in Jaboticabal County, SP, Brazil. The following compaction levels were tested: $T_{0}=0$ (no tractor passing), $T_{1^{*}}=1, T_{1}=1, T_{2}=2, T_{4}=4$ and $T_{6}=$ tractor passed six times. A tractor of $11 t$ was passed over the same area adjacent to each other until all the plot soil surface was compacted. The compaction in $T_{1 * \text { Was performed when }}$ the soil was driest to obtain a lower compaction level. The experimental design was completely randomized in split plots (six compaction levels and four soybean cultivars) with four replications. Undisturbed soil samples were collected in the 0.03-0.06, 0.08$0.11,0.15-0.18$ and $0.22-0.25 \mathrm{~m}$ deep layers to evaluate the physical attributes. Soybean (Glycine max) cultivars IAC Foscarin 31, MG/BR 46 (Conquista), BRS/MG 68 (Vencedora) and IAC 8-2 were sown in December 2003. IAC Foscarim 31 was the most productive soybean cultivar. The threshold values of soil resistance to penetration above which the soybean yield decreased varied from 2.24 to $2.97 \mathrm{MPa}$, depending on the cultivars.
\end{abstract}

Index terms: soil mechanical resistance, physical attributes, Glycine max, soil density.

\section{INTRODUÇÃO}

A soja é a principal cultura de grãos do Brasil, que é o segundo maior produtor e exportador desta "comodite", e detém a maior produtividade média mundial $\left(2,66 \mathrm{t} \mathrm{ha}^{-1}\right)$ (AGRIANUAL, 2006). Essa produtividade é obtida por meio da utilização expressiva de fertilizantes e defensivos no cultivo dessa oleaginosa. No processo produtivo, porém, a compactação do solo promovida por máquinas e equipamentos é complexa e, geralmente, afeta as relações físicas, químicas e biológicas, que atuam no desenvolvimento e na produtividade das culturas (Håkansson \& Medvedev, 1995).

Na agricultura moderna, a compactação do solo é causada principalmente pelo tráfego de máquinas com peso excessivo por eixo e que trafegam quando o solo está muito úmido, atingindo cerca de 68 milhões de hectares no mundo (Flowers \& Lal, 1998). Essa compactação promove uma alteração estrutural e reorganização das partículas do solo (Hamblim, 1985), causando o aumento da densidade e o decréscimo do volume de poros de maior diâmetro (Dexter, 2004), verificados, com maior freqüência e intensidade, em solos cultivados em sistema plantio direto, no qual ocorre menor revolvimento do solo (Hill et al., 1985).

Na planta, a compactação do solo reduz o crescimento radicular por impedimento mecânico, aeração deficiente e menor taxa de absorção de água e nutrientes, causando decréscimos significativos de produtividade (Håkansson \& Voorhees, 1998; Flowers \& Lal, 1998; Beutler \& Centurion, 2003). Esse decréscimo do crescimento radicular decorre da incapacidade de as raízes manterem a pressão de turgor suficiente para mover as partículas de solo na zona de elongação radicular (Atwell, 1990a). Conseqüentemente, ocorre deposição de microfibras de celulose longitudinais nas paredes das células primárias do córtex das raízes, inibindo o crescimento axial e promovendo o crescimento lateral das camadas de células externas do córtex das raízes (Veen, 1982). Assim, o sistema radicular menos desenvolvido absorve menos água e, conseqüentemente, reduz o potencial de água e a pressão de turgor das raízes, aumentando a produção e concentração de ácido abscísico (ABA). $\mathrm{O} A B A$ é enviado à parte aérea das plantas via xilema, atuando como principal mensagem química (Mulholland et al., 1996) que leva a planta a diminuir a condutância estomatal, atividade fotossintética e expansão foliar (Davies et al., 1994). Ainda, há maior demanda de carboidratos pelas raízes, resultando em menor alocação de C para a parte aérea (Atwell, 1990b; Tubeileh et al., 2003) e, conseqüentemente, decréscimo de produtividade da cultura que se desenvolve sob estresse por causa da compactação do solo.

A compactação do solo tem sido quantificada por atributos físicos, dentre esses a resistência à penetração tem sido mais freqüentemente utilizada por apresentar melhores correlações com o crescimento radicular (Taylor \& Gardner, 1963) e com a produtividade (Henderson, 1989), por ser sensível ao manejo e ter relações diretas com o crescimento radicular e com a produtividade das plantas (Letey, 1985; Bengough et al., 2001). A resistência à penetração (RP), por sua vez, mantém relações intrínsecas com o conteúdo de água, densidade do solo e composição granulométrica. O conteúdo de água na capacidade de campo tem sido aceito como padrão à determinação da RP na capacidade de campo, sendo, essencialmente, um ponto de referência para o estabelecimento de valores de RP críticos (Henderson, 1989; Smith et al., 1997; Bengough et al., 2001). 
Valores de RP acima de 2,0 MPa impedem o crescimento radicular de algodão (Gossypium hirsutum) (Taylor et al., 1966). Varquez et al. (1989), estudando sistemas de manejo e compactação do solo, verificaram que a produtividade máxima de soja esteve associada à RP de 1,57 a 1,59 MPa (camada de 0,05$0,35 \mathrm{~m}$ ), com decréscimos quando a RP aumentou. Silva et al. (2000) verificaram em Latossolo Vermelho argiloso que a produtividade de soja foi adequada até a RP de 1,80 MPa. Queiroz-Voltan et al. (2000) verificaram que o valor de RP crítico para a produtividade de soja varia com o cultivar.

$\mathrm{Na}$ literatura, os conhecimentos científicos mostram que a compactação do solo é praticamente inevitável na agricultura moderna e que é necessário estabelecer valores limites de compactação para proteger o solo do tráfego excessivo e manejá-lo de forma a evitar perdas de produtividade e proteger o meio ambiente, com destaque para sistemas sem revolvimento do solo. Assim, um manejo adequado do solo permite reduzir gastos por unidade de produção, conforme discutido em Håkansson \& Medvedev (1995).

A hipótese deste estudo é de que os cultivares de soja são susceptíveis à compactação do solo e apresentam respostas diferenciadas. Assim, objetivouse avaliar o desenvolvimento de cultivares de soja de acordo com a compactação do solo.

\section{MATERIAL E MÉTODOS}

O experimento foi realizado em Jaboticabal, SP (21 ${ }^{\circ} 15^{\prime} 29^{\prime}$ " S e $48^{\circ} 16^{\prime} 53^{\prime} \mathrm{W} ; 600 \mathrm{~m}$ de altitude). O clima é do tipo Cwa, segundo a classificação de Köppen. O solo utilizado foi o Latossolo Vermelho distrófico típico textura média A moderado caulinítico hipoférrico (LVd), cuja composição granulométrica foi determinada em amostras deformadas, por meio da dispersão com $\mathrm{NaOH}\left(0,1 \mathrm{~mol} \mathrm{~L}^{-1}\right)$, agitação lenta, durante $16 \mathrm{~h}$, e determinação da argila pelo método da pipeta (Gee \& Bauder, 1986). Na camada de 0,0- 0,20 m, o LVd apresentou valores médios de $330 \mathrm{~g} \mathrm{~kg}^{-1}$ de argila, 35 de silte, 635 de areia, $15 \mathrm{~g} \mathrm{dm}^{-3}$ de matéria orgânica e densidade de partículas de $2,82 \mathrm{Mg} \mathrm{m}^{-3}$.

O solo foi analisado quimicamente, segundo método citado por Raij et al. (1987), e adubado para obtenção da produtividade esperada de soja de 3,5 a 4,0 t ha-1, segundo Raij et al. (1996).

O delineamento experimental foi inteiramente casualizado com parcelas subdivididas (seis níveis de compactação e quatro cultivares), com quatro repetições, totalizando 96 subparcelas de $6,75 \mathrm{~m}^{2}$.

Antes da instalação do experimento, foram realizadas: uma escarificação do solo até $0,30 \mathrm{~m}$ de profundidade, uma gradagem niveladora, uma aplicação de calcário para elevar a saturação por bases a $60 \%$ e uma gradagem aradora $(0,12 \mathrm{~m}$ de profundidade). No início de novembro de 2003, dois dias após a chuva, quando o conteúdo de água estava próximo à capacidade de campo $(100 \mathrm{hPa})$, foram realizados os tratamentos de compactação: $\mathrm{T}_{0}=0 ; \mathrm{T}_{1^{*}}$. $=1 ; \mathrm{T}_{1}=1 ; \mathrm{T}_{2}=2 ; \mathrm{T}_{4}=4$ e $\mathrm{T}_{6}=$ seis passadas, no mesmo local, de um trator de $11 \mathrm{t}$ com dois eixos e quatro pneus de mesma largura $(0,40 \mathrm{~m})$ e pressão interna, uma ao lado da outra, no sentido do declive da área, perfazendo toda a superfície do solo. No tratamento $\mathrm{T}_{1^{*}}$, a compactação ocorreu quatro dias após a chuva, em condição de solo mais seco, para obter um menor nível de compactação.

Dia 24 de novembro de 2003, as sementes de soja dos cultivares de ciclo precoce (120 dias): IAC Foscarin 31; e de ciclo médio (131-140 dias): MG/ BR 46 (Conquista), BRS/MG 68 (Vencedora) e IAC 82 foram inoculadas com Bradyrhizobium japonicum e semeadas, com semeadora de plantio direto, na profundidade de $0,05 \mathrm{~m}$ e no espaçamento de $0,45 \mathrm{~m}$ entrelinhas, no sentido transversal ao declive da área. A emergência, porém, foi muito reduzida, sendo realizada nova semeadura manual, nas mesmas linhas, dia cinco de dezembro. Após sete dias, realizouse o desbaste, deixando 20 plantas por metro linear. Foi feita a aplicação de epoxiconazole + pyraclostrobin, dia 10/02/2004, no cultivar IAC Foscarim 31, para o controle do oídio (Microsphaera diffusa), e de Tebuconazole, dia 26/02, 03/03 e 15/03, em todos os cultivares, para o controle da ferrugem asiática (Phakopsora pachyrhizi).

Dois meses após a aplicação dos níveis de compactação, dia 03 de janeiro, foram coletadas duas amostras por tratamento, na entrelinha, com cilindros de $0,03 \mathrm{~m}$ de altura e $0,048 \mathrm{~m}$ de diâmetro $\left(53,16 \times 10^{-6} \mathrm{~m}^{3}\right)$, nas camadas de $0,03-0,06$, $0,08-0,11,0,15-0,18$ e $0,22-0,25 \mathrm{~m}$, para determinação dos atributos físicos. As amostras foram saturadas, durante $24 \mathrm{~h}$, e submetidas à tensão de $60 \mathrm{hPa}$, pesadas e, em seguida, submetidas à tensão $100 \mathrm{hPa}$ equivalente à capacidade de campo (Reichardt, 1988) em câmaras de Richards com placa porosa (Klute, 1986). Ao atingir o equilíbrio, na tensão de $100 \mathrm{hPa}$, as amostras foram pesadas e submetidas à determinação da resistência do solo à penetração (RP), com duas subdeterminações por amostra. A RP foi determinada com o penetrômetro eletrônico estático de laboratório com velocidade constante de penetração de $0,01 \mathrm{~m} \mathrm{~min}^{-1}$, registro de uma leitura por segundo, cone com semi-ângulo de $30^{\circ}$ e área de $3,14 \times 10^{-6} \mathrm{~m}^{2}$, equipado com atuador linear e célula de carga de 20 kgf acoplada a um microcomputador para a aquisição dos dados, conforme descrito por Tormena et al. (1998) e por Bengough et al. (2001). Foram utilizadas 100 leituras por subdeterminação, correspondentes à camada central do cilindro de 0,007 a 0,024 m, e calculado o valor médio das 200 leituras (duas subdeterminações) para representar a RP da amostra. 
Nestas amostras, foram avaliadas a densidade do solo (Blake \& Hartge, 1986); a microporosidade, por secagem (tensão de $60 \mathrm{hPa}$ ), em câmaras de pressão de Richards com placa porosa (Klute, 1986); a porosidade total segundo Danielson \& Sutherland (1986), e a macroporosidade, obtida pela diferença entre a porosidade total e a microporosidade.

Nas plantas, foram avaliados a altura e a matéria seca da parte aérea, o número de vagens e grãos por planta, peso de 100 sementes e a produtividade dos cultivares de soja. O nível de desfolha foi avaliado por meio de uma escala visual de notas, variando de 0 a 5 , sendo $0=$ sem desfolha; $1=$ muito poucas a $10 \%$; 2 $=11$ a $25 \%$; $3=26$ a $50 \% ; 4=51$ a $75 \%$; e $5=$ mais de $75 \%$ de desfolha. Após a colheita, foram coletadas, na linha, 16 subamostras de solo por repetição do cultivar BRS/MG 68 (Vencedora), nas camadas de 0,0 0,$05 ; 0,05-0,10$ e $0,10-0,20 \mathrm{~m}$, que foram homogeneizadas para a retirada de uma amostra composta, para análise química.

Os resultados foram submetidos à análise de variância, e as médias foram comparadas pelo teste de Tukey a $5 \%$. Foram realizadas análises de regressão entre a resistência do solo à penetração e a produtividade de soja.

\section{RESULTADOS E DISCUSSÃO}

O tráfego do trator sobre o solo aumentou a compactação, verificada pelo aumento da $R P$, da Ds e da microporosidade, e reduziu a quantidade de poros de maior diâmetro (macroporos) (Quadro 1), corroborando os resultados de Hill et al. (1985) e Tubeileh et al. (2003). A alteração do diâmetro de poros e da Ds foi mais pronunciada após uma passada do trator sobre a superfície do solo $\left(\mathrm{T}_{1}\right)$, com menores efeitos quando aumentou o número de passadas, conforme Horn et al. (1995). Isso, por serem os poros de maior diâmetro (macroporos) menos resistentes e se deformarem formando poros de menor diâmetro que são mais resistentes e suportam maiores pressões.

Dentre os atributos físicos, a resistência do solo à penetração, determinada no conteúdo de água retida na tensão de $100 \mathrm{hPa}$, apresentou valores distribuídos na faixa entre solo não compactado $\left(\mathrm{T}_{0}\right)$ e solo compactado $\left(\mathrm{T}_{6}\right)$, em relação à porosidade e Ds do solo que tiveram grande alteração após o tráfego inicial $\left(\mathrm{T}_{1^{*}}\right)$ e pequenas alterações do $\mathrm{T}_{1}$ ao $\mathrm{T}_{6}$. Ainda, por meio desses atributos, verificou-se que o efeito do tráfego do trator sobre a superfície do solo provavelmente não atingiu a camada de $0,22-0,25 \mathrm{~m}$, porque não foi observada tendência de aumento de valores de RP e Ds com o aumento do número de passadas de trator, fato relacionado, segundo Håkansson \& Medvedev (1995), com o baixo peso do trator por eixo $(5,5 \mathrm{t})$. Segundo esses pesquisadores, a profundidade que o solo se compacta pelo tráfego de máquinas sobre a superfície, em geral, atinge até $0,25-$ $0,30 \mathrm{~m}$, podendo ser menor ou maior de acordo com o peso das máquinas por eixo, da pressão dos pneus, do conteúdo de água e do tipo de solo.

Por essa razão, foram utilizados os valores de $\mathrm{RP}$ médios da camada de $0,03-0,18 \mathrm{~m}$, na discussão com a produtividade dos cultivares de soja. Além disso, o

Quadro 1. Valores médios dos atributos físicos em decorrência do número de passadas de trator sobre o Latossolo Vermelho

\begin{tabular}{|c|c|c|c|c|c|c|c|c|c|c|c|c|}
\hline \multirow{2}{*}{ Camada } & \multicolumn{12}{|c|}{ Passada de trator (11 t) } \\
\hline & $\mathbf{T}_{0}(1)$ & $\mathbf{T}_{1 *}$ & $\mathbf{T}_{1}$ & $\mathbf{T}_{2}$ & $\mathbf{T}_{4}$ & $\mathbf{T}_{6}$ & $\mathbf{T}_{0}$ & $\mathbf{T}_{1 *}$ & $\mathbf{T}_{1}$ & $\mathbf{T}_{2}$ & $\mathbf{T}_{4}$ & $\mathbf{T}_{6}$ \\
\hline $\mathrm{m}$ & \multicolumn{6}{|c|}{ Resistência à penetração (MPa ) } & \multicolumn{6}{|c|}{ Densidade do solo $\left(\mathrm{Mg} \mathrm{m}^{-3}\right)$} \\
\hline $0,03-0,06$ & 1,09 & 1,31 & 2,72 & 3,80 & 4,01 & 4,54 & 1,39 & 1,49 & 1,66 & 1,70 & 1,71 & 1,75 \\
\hline $0,08-0,11$ & 0,82 & 1,64 & 2,75 & 3,25 & 3,45 & 4,38 & 1,31 & 1,58 & 1,68 & 1,70 & 1,71 & 1,69 \\
\hline $0,15-0,18$ & 1,56 & 2,18 & 2,47 & 2,93 & 3,43 & 4,34 & 1,46 & 1,62 & 1,66 & 1,67 & 1,63 & 1,66 \\
\hline $0,22-0,25$ & 1,75 & 1,56 & 2,25 & 2,04 & 2,07 & 2,17 & 1,60 & 1,54 & 1,57 & 1,60 & 1,54 & 1,53 \\
\hline \multirow[t]{2}{*}{$0,03-0,18$} & 1,16 & 1,71 & 2,65 & 3,33 & 3,63 & 4,42 & 1,39 & 1,56 & 1,67 & 1,69 & 1,68 & 1,70 \\
\hline & \multicolumn{6}{|c|}{ Macroporosidade $\left(\mathrm{m}^{3} \mathrm{~m}^{-3}\right)$} & \multicolumn{6}{|c|}{ Microporosidade $\left(\mathrm{m}^{3} \mathrm{~m}^{-3}\right)$} \\
\hline $0,03-0,06$ & 0,17 & 0,10 & 0,04 & 0,03 & 0,04 & 0,04 & 0,27 & 0,29 & 0,28 & 0,28 & 0,28 & 0,29 \\
\hline $0,08-0,11$ & 0,18 & 0,12 & 0,05 & 0,04 & 0,04 & 0,05 & 0,26 & 0,29 & 0,28 & 0,30 & 0,28 & 0,29 \\
\hline $0,15-0,18$ & 0,10 & 0,07 & 0,05 & 0,05 & 0,06 & 0,06 & 0,26 & 0,29 & 0,28 & 0,29 & 0,29 & 0,30 \\
\hline $0,22-0,25$ & 0,06 & 0,08 & 0,08 & 0,08 & 0,08 & 0,08 & 0,29 & 0,30 & 0,29 & 0,28 & 0,30 & 0,30 \\
\hline $0,03-0,18$ & 0,15 & 0,10 & 0,05 & 0,04 & 0,05 & 0,05 & 0,26 & 0,29 & 0,28 & 0,29 & 0,29 & 0,29 \\
\hline
\end{tabular}

\footnotetext{
(1) $\mathrm{T}_{0}=0 ; \mathrm{T}_{1^{*}}=1 ; \mathrm{T}_{1}=1 ; \mathrm{T}_{2}=2 ; \mathrm{T}_{4}=4 \mathrm{e} \mathrm{T}_{6}=$ seis passadas de um trator de $11 \mathrm{t}$, no mesmo local, no conteúdo de água próximo à capacidade de campo. No tratamento $\mathrm{T}_{1^{*}}$ o tráfego foi realizado quando o solo estava mais seco.
} 
valor médio de RP nessa camada mostrou uma estreita relação com a produtividade da soja, visto que $77 \%$ do sistema radicular da cultura situa-se na camada de 0,0-0,20 m, segundo Böhm et al. (1977).

A altura das plantas de soja decresceu a partir de duas passadas do trator no mesmo local $\left(\mathrm{T}_{2}\right)$, e a matéria seca e o número de vagens não diferiram entre os níveis de compactação e entre os cultivares (Quadro 2). Já o peso de 100 sementes foi maior a partir de uma passada de trator sobre o solo com conteúdo de água retida na capacidade de campo $\left(\mathrm{T}_{1}\right)$, não diferindo entre cultivares. $\mathrm{O}$ menor peso de 100 sementes, no solo pouco compactado $\left(\mathrm{T}_{0}\right.$ e $\left.\mathrm{T}_{1^{*}}\right)$ refletiu em menor produtividade, visto que o número de vagens e de grãos por vagem não diferiu.

A menor produtividade de soja no solo não compactado $\left(\mathrm{T}_{0}\right)$ deve-se ao fato de ser uma pequena compactação benéfica por aumentar a condutividade hidráulica insaturada do solo, aumentando o transporte de nutrientes até às raízes e, ainda, fato de a maior área de contato das raízes com o solo aumentar a taxa de absorção de água e nutrientes por unidade de raiz (Veen et al., 1992). Esse fato ficou mais evidente no cultivar IAC Foscarim 31 em que o ataque de moléstias foi menor (Quadro 3). Esse efeito de uma pequena compactação (recompactação) no aumento de produtividade também foi demonstrado por Håkansson \& Medvedev (1995) e Beutler \& Centurion (2003).

Em relação ao grau de compactação do solo, a partir do qual ocorre decréscimo de produtividade, verificase que, a partir do $\mathrm{T}_{2}$, ocorreu decréscimo gradual da produtividade de todos os cultivares de soja (Figura 1). Todavia, o valor de RP a partir do qual a produtividade decresceu, verificado por meio das equações de regressão quadrática, foi menor para o cultivar IAC Foscarim $31(2,24 \mathrm{MPa})$, comparado ao valor dos cultivares MG/BR 46 (Conquista), BRS/MG 68
(Vencedora) e IAC 8-2. Isso deveu-se, parcialmente, à intensa infestação da ferrugem na área de solo menos compactado, refletindo em menor peso de 100 sementes e produtividade, comparado aos demais tratamentos de compactação, nos últimos três cultivares, modificando o valor de RP em que ocorreu a produtividade máxima.

$\mathrm{O}$ valor de $\mathrm{RP}$ adotado como impeditivo ao crescimento radicular de 2,0 $\mathrm{MPa}$ (Taylor et al., 1966; Silva et al., 1994) foi inferior aos valores a partir dos quais a produtividade dos cultivares de soja decresceu, com menor valor para o cultivar IAC Foscarim 31 $(2,24 \mathrm{MPa})$. Esses valores foram superiores aos encontrados por Varquez et al. (1989), em sistemas de manejo, em que a maior produtividade de soja foi obtida na RP de 1,57 e 1,59 $\mathrm{MPa}$, decrescendo posteriormente. Beutler (2003) verificou decréscimo de $5 \%$ da produtividade de soja cultivar 'Embrapa 48 , quando a RP passou de 0,85 a $2,00 \mathrm{MPa}$, com decréscimos acentuados a partir desse valor. Lal (1996) e Flowers \& Lal (1998) obtiveram decréscimo de $9 \%$ de produtividade de soja no solo trafegado por uma máquina de $10 \mathrm{t}$ por eixo comparado ao não trafegado.

Por sua vez, Lindemann et al. (1982) verificaram que a produtividade de soja aumentou, quando o solo foi trafegado com um trator de 3,6 t em ano com menor precipitação pluvial, e decresceu quando, ocorreram maiores precipitações, porém não significativamente. Já Barber (1994) verificou que a produtividade de soja (cultivar IAC 8), em sistemas de manejo, decresceu vários anos a partir da resistência à penetração de 2,0 a $3,0 \mathrm{MPa}$, com menores valores para anos com maior precipitação pluvial, em conseqüência de uma menor drenagem interna e deficiência de aeração no solo compactado. Esses resultados indicam que a cultura da soja é sensível à compactação do solo pelo tráfego de máquinas.

\section{Quadro 2. Valores médios dos componentes de crescimento de soja em decorrência do número de passadas} de trator sobre o Latossolo Vermelho

\begin{tabular}{lccccccc}
\hline & \multicolumn{5}{c}{ Passada do trator (11 t) } \\
\cline { 2 - 7 } & $\mathrm{T}_{0}{ }^{(2)}$ & $\mathrm{T}_{1^{*}}$ & $\mathrm{~T}_{1}$ & $\mathrm{~T}_{2}$ & $\mathrm{~T}_{4}$ & $\mathrm{~T}_{6}$ & $\mathrm{CV}(\%)$ \\
\hline Altura das plantas (m) & $0,88 \mathrm{a}(1)$ & $0,87 \mathrm{a}$ & $0,88 \mathrm{a}$ & $0,77 \mathrm{~b}$ & $0,68 \mathrm{bc}$ & $0,66 \mathrm{c}$ & 9,7 \\
Matéria seca (g/planta) & $11,9 \mathrm{a}$ & $12,9 \mathrm{a}$ & $12,3 \mathrm{a}$ & $11,1 \mathrm{a}$ & $10,7 \mathrm{a}$ & $10,7 \mathrm{a}$ & 18,7 \\
Número de vagens/planta & $22,4 \mathrm{a}$ & $24,4 \mathrm{a}$ & $24,5 \mathrm{a}$ & $23,3 \mathrm{a}$ & $21,9 \mathrm{a}$ & $21,5 \mathrm{a}$ & 28,6 \\
Número de grãos/planta & $40,6 \mathrm{ab}$ & $42,6 \mathrm{ab}$ & $48,0 \mathrm{a}$ & $40,4 \mathrm{ab}$ & $38,7 \mathrm{ab}$ & $33,1 \mathrm{~b}$ & 30,8 \\
Peso de 100 sementes (g) & $14,2 \mathrm{~b}$ & $14,3 \mathrm{~b}$ & $15,5 \mathrm{a}$ & $15,7 \mathrm{a}$ & $15,6 \mathrm{a}$ & $15,7 \mathrm{a}$ & 4,9
\end{tabular}

(1) Médias, na linha, seguidas pela mesma letra não diferem entre si pelo teste de Tukey a $5 \%{ }^{(2)} \mathrm{T}_{0}=0 ; \mathrm{T}_{1^{*}}=1 ; \mathrm{T}_{1}=1 ; \mathrm{T}_{2}=2 ; \mathrm{T}_{4}$ $=4 \mathrm{e} \mathrm{T}_{6}=6$ passadas de um trator de $11 \mathrm{t}$, no mesmo local, no conteúdo de água próximo à capacidade de campo. No tratamento $\mathrm{T}_{1^{*}}$ o tráfego foi realizado quando o solo estava mais seco. A interação entre a compactação do solo e esses componentes de desenvolvimento dos cultivares de soja não foi significativa a $5 \%$. 
O decréscimo da produtividade dos cultivares de soja por causa da compactação pelo tráfego do trator, verificado neste estudo, a partir da $\mathrm{RP}$ de 2,24 a 2,97 MPa (Figura 1) ocorreu por diversas causas. Dentre essas, Lipiec et al. (1993) afirmaram que solos compactados promovem alterações morfológicas das raízes, resultando em menor comprimento, distribuição espacial e área superficial por causa do impedimento físico, da menor continuidade, quantidade e diâmetro de poros, resultando, conseqüentemente, em menor volume de solo explorado. Isso reduz a taxa de uso de água pelas raízes, que tem uma correlação linear com o peso de matéria seca da parte aérea das plantas (Lipiec et al.,
1993; Lal, 1996). Além do mais, diminui a eficiência de absorção de nutrientes e a quantidade de nitrogênio fixado pela leguminosa (Lindemann et al., 1982; Grath \& Håkansson, 1992).

Os cultivares de soja apresentaram respostas diferenciais à compactação do solo (Quadro 4 e Figura 1), corroborando os resultados de QueirozVoltan et al. (2000) segundo os quais o cultivar IAC14 adaptou-se melhor à compactação, comparado ao cultivar IAC-8. A maior produtividade de soja do cultivar IAC Foscarim 31, fato parcialmente relacionado com a menor infestação da ferrugem asiática nesse cultivar, o qual, em virtude do estádio final do ciclo, comparado ao dos demais que estavam

Quadro 3. Média do nível de desfolha de quatro cultivares de soja, transformados em $\sqrt{\mathrm{x}}+0,5$, e estádios de desenvolvimento em níveis de compactação em Latossolo Vermelho, 15 dias após o aparecimento dos sintomas visíveis

\begin{tabular}{cccccc}
\hline \multirow{2}{*}{$\begin{array}{c}\text { Desfolha } \\
\text { (estádio de desenvolvimento) }\end{array}$} & \multicolumn{5}{c}{ Passada do trator (11 t) } \\
\cline { 2 - 6 } & $\mathbf{T}_{0}{ }^{(2)}$ & $\mathbf{T}_{1^{*}}$ & $\mathbf{T}_{1}$ & $\mathbf{T}_{2}$ & $\mathbf{T}_{4}$ \\
\hline
\end{tabular}

Nível de desfolha

Estádio de desenvolvimento( ${ }^{(2)}$

R 7.3

$2,12 \mathrm{bc}^{(1)}$

2,34 a

Nível de desfolha

Estádio de desenvolvimento

$2,29 \mathrm{a}$

R 5.5

2,18
R 5.5

2,23 a

Nível de desfolha

Estádio de desenvolvimento

R 5.3

$2,12 \mathrm{ab}$
$\mathrm{R} 5.4$

2,12 a

R 5.3
Nível de desfolha

Estádio de desenvolvimento

$2,12 \mathrm{a}$

R 5.4

IAC Foscarim 31

$2,29 \mathrm{ab}$
$\mathrm{R} 7.5$

R 7.4

$2,12 \mathrm{bc}$

MG/BR 46 (Conquista)

\begin{tabular}{cc}
$1,87 \mathrm{~b}$ & \multicolumn{1}{c}{$1,87 \mathrm{~b}$} \\
$\mathrm{R} 5.5$ & $\mathrm{R} 5.5$
\end{tabular}

$1,87 \mathrm{~b}$

R 5.5

$2,12 \mathrm{bc}$

R 8.2

$2,05 \mathrm{c}$

R 8.1

BRS/MG 68 (Vencedora)

(1) Médias seguidas pela mesma letra, na linha, não diferem pelo teste de Tukey a $5 \%$. ${ }^{(2)}$ Estádio de desenvolvimento da soja segundo escala de Fehr (1971). ${ }^{(2)} \mathrm{T}_{0}=0 ; \mathrm{T}_{1^{*}}=1 ; \mathrm{T}_{1}=1 ; \mathrm{T}_{2}=2 ; \mathrm{T}_{4}=4 \mathrm{e} \mathrm{T}_{6}=$ seis passadas de um trator de $11 \mathrm{t}$, no mesmo local, no conteúdo de água próximo à capacidade de campo. No tratamento $\mathrm{T}_{1^{*}}$ o tráfego foi realizado quando o solo estava mais seco.

Quadro 4. Quadro de análise de variância da produtividade de cultivares de soja em níveis de compactação, em Latossolo Vermelho

Causa da variação

Compactação (Parcela)

Cultivares (Subparcela)

Interação P x S

Total
Grau de liberdade

F

\begin{tabular}{lrc}
\hline Compactação (Parcela) & 5 & $27,61^{* *}$ \\
Cultivares (Subparcela) & 3 & $107,51^{* *}$ \\
Interação P x S & 15 & $2,23^{*}$ \\
Total & 95 & \\
\hline
\end{tabular}




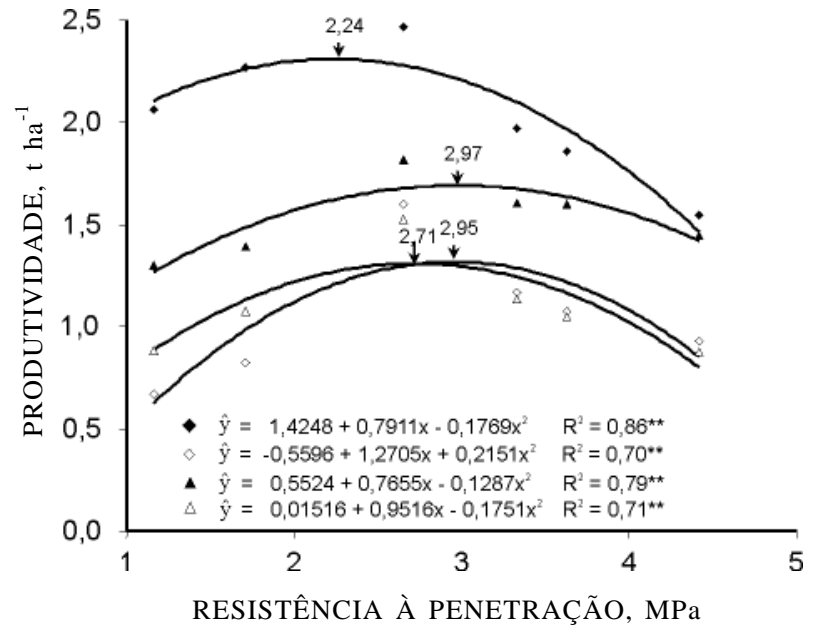

Figura 1. Produtividade de cultivares de soja, considerando a resistência do solo à penetração, em Latossolo Vermelho. (४) IAC Foscarim 31; $(\diamond)$ MG/BR 46 (Conquista); (ム) BRS/MG 68 (Vencedora); ( $\Delta$ ) IAC 8-2

na fase de enchimento de grãos (estádio R5) (Quadro 3) e que necessitavam das folhas para realizar fotossíntese, pôde encher normalmente os grãos e, assim, expressar o potencial produtivo.

A produtividade dos cultivares de soja foi aquém do esperado (3,5 a 4,0 t ha-1). Isso ocorreu porque, além da ocorrência da ferrugem asiática, na primeira semeadura realizada dia 24 de novembro, quando as precipitações pluviais começaram a ocorrer com mais freqüência, não houve a emergência de 20 plantas por metro linear, stand adequado para a máxima produtividade. Assim, a segunda semeadura foi realizada dia cinco de dezembro de 2004 , data posterior ao período ideal de 15/10 a 30/11, para obtenção da máxima produtividade, considerando o fotoperíodo da cultura.

Finalmente, a menor produtividade de todos os cultivares de soja no solo menos compactado $\left(\mathrm{T}_{0} \mathrm{e}_{1_{1}}\right.$ ) (Figura 1) deveu-se, parcialmente, à maior infestação de moléstias e à queda de folhas das plantas (Quadro 3). No cultivar IAC Foscarim 31, ocorreu ataque de oídio que foi controlado com uma pulverização de epoxiconazole + pyraclostrobin com menores prejuízos a produtividade, além de já estar em final de ciclo quando do ataque da ferrugem nos demais cultivares. No entanto, nos cultivares MG/ BR 46 (Conquista), BRS/MG 68 (Vencedora) e IAC 82 ocorreram intensos ataques de ferrugem asiática visível a partir do dia 22/02, quando ocorreram altas temperaturas e umidade favoráveis ao rápido desenvolvimento da moléstia. Por causa das chuvas, a pulverização com Tebuconazole foi realizada apenas cinco dias após, o que provocou redução drástica da produtividade.

Todavia, o maior decréscimo de produtividade por causa dessas moléstias ocorreu no solo menos compactado, por ser a planta maior. Isso diminui não só a circulação de ar e permite a permanência da folha mais úmida e por mais tempo, favorecendo o desenvolvimento da doença, mas também diminui a eficiência de aplicação do fungicida por causa do maior desenvolvimento foliar das plantas. Esse efeito nocivo da doença sobre a produtividade está demonstrado por meio da menor produtividade de soja nesses cultivares, no $\mathrm{T}_{0}$ e $\mathrm{T}_{1^{*}}$, comparada à produtividade obtida no cultivar IAC Foscarim 31. Esse decréscimo de produtividade da soja causado pela ferrugem asiática deveu-se também à doença ocorrida, pela primeira vez, na região, fato que dificultou o monitoramento e controle da doença.

\section{CONCLUSÕES}

1. A produtividade de soja decresceu a partir de valores de resistência do solo à penetração de $2,24 \mathrm{a}$ $2,97 \mathrm{MPa}$

2. $\mathrm{O}$ valor de resistência à penetração a partir do qual ocorreu redução da produtividade variou entre cultivares.

\section{LITERATURA CITADA}

AGRIANUAL 2006: Anuário da agricultura brasileira. São Paulo, FNP Consultoria e Comércio, 2006. p.433-468.

ATWELL, B.J. The effect of soil compaction on wheat during early tillering: I. Growth, development and root structure. New Phytol., 115:29-35, 1990a.

ATWELL, B.J. The effect of soil compaction on wheat during early tillering: III. Fate of carbon transported to the root structure. New Phytol., 115:43-49, 1990b.

BARBER, R.G. Persistence of loosened horizons and soybean yield increases in Bolivia. Soil Sci. Soc. Am. J., 58:943$950,1994$.

BENGOUGH, A.G.; CAMPBELL, D.J. \& O’SUlLIVAN, M.F. Penetrometer techniques in relation to soil compaction and root growth. In: SMITH, K.A. \& MULLINS, C.E, eds. Soil environmental analysis: physical methods. 2.ed. Marcel Decher, 2001. p.377-403.

BEUTLER, A.N. Efeito da compactação do solo e do conteúdo de água nas características agronômicas de soja e arroz de sequeiro. Jaboticabal, Universidade Estadual Paulista, 2003. 126p. (Tese de Doutorado)

BEUTLER, A.N. \& CENTURION, J.F. Efeito do conteúdo de água e da compactação do solo na produção de soja. Pesq. Agropec. Bras., 38:849-856, 2003.

BLAKE, G.R. \& HARTGE, K.H. Bulk density. In: KLUTE, A., ed. Methods of soil analysis: Physical and mineralogical methods. 2.ed. Madison, American Society of Agronomy, 1986. Part 1, p.363-375.

BÖHM, W.; MADUAKOR, H. \& TAYLOR, H.M. Comparison of five methods for characterizing soybean rooting density and development. Agron. J., 69:415-419, 1977. 
DANIELSON, R.E. \& SUTHERLAND, P.L. Porosity. In: KLUTE, A., ed. Methods of soil analysis. 2.ed. Madison, American Society of Agronomy, 1986. Part 1. p.443-461.

DAVIES, W.J.; TARDIEU, F. \& TREJO, C.L. How do chemical signals work in plants that grow in drying soil?. Plant Physiol., 104:309-314, 1994.

DEXTER, A.R. Soil physical quality: Theory, effects of soil texture, density, and organic matter, and effects on root growth. Part 1. Geoderma, 120:201-214, 2004.

FEHR, W.R.; GAVINESS, C.E.; BURMOOD, D.T. \& PENNINGTON, J.S. Stage of development description for soybeans (Glycine $\max (\mathrm{L})$ Merrill). Crop Sci., 11:929931, 1971.

FLOWERS, M.D. \& LAL, R. Axle load and tillage effects on soil physical properties and soybean grain yield on a Molic Ochraqualf in Northwest. Soil Till. Res., 48:21-35, 1998.

GEE, G.W. \& BAUDER, J.W. Particle-size analysis. In: KLUTE, A., ed. Methods of soil analysis. 2.ed. Madison, American Society of Agronomy, 1986. Part 1. p.383-411.

GRATH, T. \& HAKANSSON, I. Effects of soil compaction on develompement and nutrient uptake of peas. Swed. J. Agric. Res., 22:13-17, 1992.

HÅKANSSON, I. \& MEDVEDEV, V.W. Protection of soils from mechanical overloading by establishing limits for stresses caused by heavy vehicles. Soil Till. Res., 35:8597, 1995.

HÅKANSSON, I. \& VOORHEES, W.B. Soil compaction. In: LAL, R.; BLUM, W.H.; VALENTINE, C. \& STEWARD, B.A. Methods for assessment of soil degradation. Boca Raton, CRS Press, 1998. p.167-179 (Advances in Soil Science).

HAMBLIM, A.P. The influence of soil structure on water movement, crop root growth and water uptake. Adv. Agron., 38:95-158, 1985.

HENDERSON, C.W.L. Using a penetrometer to predict the effects of soil compaction on the growth and yield of wheat on uniform, sandy soils. Aust. J. Agric. Res., 40:497-508, 1989.

HILL, R.L.; HORTON, R. \& CRUSE, R.M. Tillage effects no soil water retention and pore size distribution of two mollisols. Soil Sci. Soc. Am. J., 49:1264-1270, 1985.

HORN, R.; DOMZAL, H.; SLOWINSKA-JURKIEWICZ, A. \& van OUWERKERK, C. Soil compaction processes and their effects on the structure of arable soils and the environment. Soil Till. Res., 35:23-36, 1995.

KLUTE, A. Water retention: Laboratory methods. In: KLUTE, A., ed. Methods of soil analysis. 2. ed. Madison, American Society of Agronomy, 1986. Part 1. p.635-662.

LAL, R. Axle load and tillage effects on crop yield on a Mollic Ochraqualf in Northwest Ohio. Soil Till. Res., 37:143-160, 1996.

LETEY, J. Relationship between soil physical properties and crop production. Adv. Soil Sci., 1: 277-294, 1985.

LINDEMANN, W.C.; HAM, G.E. \& RANDALL, G.W. Soi compaction effects on soybean nodulation, $\mathrm{N}_{2}\left(\mathrm{C}_{2} \mathrm{H}_{4}\right)$ fixation and seed yield. Agron. J., 74:307-311, 1982.

LIPIEC, J.; ISHIOKA, T.; HATANO, R. \& SAKUMA, T. Effects of soil structural discontinuity on root and shoot growth and water use of maize. Plant Soil, 157:65-74, 1993.
MULHOLLAND, B.J.; BLACK, C.R.; TAYLOR, I.B; ROBERTS, J.A. \& LENTON, J.R. Effect of soil compaction on barley (Hordeum vulgare L.) growth. I. Possible role for ABA as a root-sourced chemical signal. J. Exp. Bot., 47:539-549, 1996.

QUEIROZ-VOLTAN, R.B.; NOGUEIRA, S.S.S. \& MIRANDA, M.A.C. Aspectos da estrutura da raiz e do desenvolvimento de plantas de soja em solos compactados. Pesq. Agropec. Bras., 35:929-938, 2000

RAIJ, B. van; CANTARELlA, H.; QUAGGIO, J.H. \& FURLANI, A.M.C. Recomendação de adubação e calagem para o Estado de São Paulo. 2.ed. Campinas, Instituto Agronômico \& Fundação IAC, 1996. 285p. (Boletim Técnico, 100)

RAIJ, B. van; QUAGGIO, J.A.; CANTARELLA, H.; FERREIRA, M.E.; LOPES, A.S. \& BATAGLIA, O.C. Análise química do solo para fins de fertilidade. Campinas, Fundação Cargill, 1987. 170p.

REICHARDT, K. Capacidade de campo. R. Bras. Ci. Solo, $12: 211-216,1988$

SILVA, A.P.; KAY, B.D. \& PERFECT, E. Characterization of the least limiting water range. Soil Sci. Soc. Am. J., 58:1775-1781, 1994.

SILVA, V.R.; REINERT, D.J. \& REICHERT, J.M. Resistência mecânica do solo à penetração influenciada pelo tráfego de uma colhedora em dois sistemas de manejo do solo. $\mathrm{Ci}$. Rural, 30:795-801, 2000.

SMITH, C.W.; JOHNSTON, M.A. \& LORENTZ, S. The effect of soil compaction and soil physical properties on the mechanical resistance of South African forestry soils. Geoderma, 78:93-111, 1997.

TAYLOR, H. \& GARDNER, H. Penetration of cotton seedling taproots as influenced by bulk density, moisture content, and strength. Soil Sci., 963:153-156, 1963.

TAYLOR, H.M.; ROBERSON, G.M. \& PARKER Jr., J.J. Soil strength-root penetration relations to medium to coarsetextured soil materials. Soil Sci., 102:18-22, 1966.

TORMENA, C.A.; SILVA, A.P. \& LIBARDI, P. Caracterização do intervalo hídrico ótimo de um Latossolo Roxo sob plantio direto. R. Bras. Ci. Solo, 22:573-581, 1998.

TUBEILEH, A.; GROLEAU-RENAUD, V.; PLANTUREUX, S. \& GUCKERT, A. Effect of soil compaction on photosynthesis and carbon partitioning within a maizesoil system. Soil Till. Res., 71:151-161, 2003.

VARQUEZ, L.; MYHRE, D.L.; GALLAHER, R.N.; HANLON, E.A. \& PORTIER, K.M. Soil compaction associated with tillage treatments for soybean. Soil Till. Res., 13:35-45, 1989.

VEEN, B.W. The influence of mechanical impedance on the growth of maize roots. Plant Soil, 66:101-109, 1982.

VEEN, B.W.; NOORDWIJK, M.; WILLIGEN, P.; BOONE, F.R. \& KOOISTRA, M.J. Root-soil contact of maize, as measured by a thin-section technique. III. Effects on shoot growth, nitrate and water uptake efficiency. Plant Soil, 139:131-138, 1992. 